\title{
How binding compounds interfere in the in vitro rumen degradability results of the gas production bioassay for tannins
}

I.C.S. Bueno ${ }^{1}$, P.B. Godoy ${ }^{2}$, A.L. Abdalla ${ }^{2}$

${ }^{1}$ Faculty of Animal Science and Food Engineering, University of São Paulo, Pirassununga, SP, Brazil

${ }^{2}$ Centre for Nuclear Energy in Agriculture, University of São Paulo, Piracicaba, SP, Brazil

Email: ivesbueno@usp.br

Introduction The tannin bioassay is widely used to evaluate the effects of tannins on the rumen fermentation. To attenuate the tannin interference, polyethylene glycol (PEG) is used as binding compound. In presence of PEG, the complex formed by tannins and feed nutrients is broken and a new complex, more stable, is formed by PEG and tannins. Another compound used as binding compound is the polyvinyl polypyrrolidone (PVPP). The aim of this work was to evaluate the effect of addition of binding compounds on the degradability results of the gas production bioassay for tannins.

Material and methods The bioassay was carried out according to Bueno et al. (2008) using five substrates (feeds) and three inocula prepared from sheep rumen liquor. The obtained gas production profiles are published in Bueno et al. (2008). The tested feeds were: feed A - aroeira (Astronian urundeuva), feed B - jurema preta (Mimosa hostilis), feed C - sorghum grain (Sorghum bicolor), and two mixtures with $45 \%$ of sorghum leaves and $45 \%$ of concentrate (maize and soybean meal) plus $10 \%$ of either quebracho (Schinopsis lorentzii) extract (feed D) or Acacia (Acacia mollissima) tannin extract (feed E). For each feed, six bottles (with $1 \mathrm{~g}$ of substrate each) were incubated for each inoculum: two as control and four with binding compounds (two with PVPP and two with PEG). Eight Santa Inês adult wethers (about $45 \mathrm{~kg}$ LW) were used as inoculum donors. For each inoculum, liquid and solid phases of rumen digesta were collected separately and the inoculum was prepared using 0.50 of each phase. Animals were fed Tifton hay and concentrate (soybean meal and maize), at the rate 70:30. The binding compounds were added to the substrate directly into the fermentation flasks (1g of binding compound per $g$ of substrate). The interference of binding compounds in degradability results was evaluated directly and using the partitioning factor ( $\mathrm{mg}$ substrate truly degraded per $\mathrm{ml}$ gas produced). Feeds and treatments were incorporated in a randomised design, in a complete factorial arrangement. Treatments (binding compounds) were compared by Tukey test.

Results The addition of PEG and PVPP promoted the increase of gas production, indicating that some feed nutrients were bound by tannins (Bueno et al., 2008). PEG showed higher affinity to the tannins than PVPP. When binding compound is added to the substrate, the complex tannin-feed nutrient is broken and a new complex is formed. The nutrients become available to fermentation (degradation), resulting in an effective increase of degradability. But the complex tannin-PEG or tannin-PVPP is insoluble and is recovered in the filtered residue. Thus either PEG or PVPP contaminate the residue and increase its weight, decreasing the degradability result (Table 1). Even free binding compounds can interfere in the results. Although PEG is water soluble, PVPP is not, and the contamination in this case is even higher. PEG promotes a great increase in degradability of tanniniferous feeds, and the results usually are higher than the control, the results would be really higher if the PEG contamination would be discounted.

Table 1 In vitro dry matter degradability and partitioning factor of five feeds incubated for 24 and $96 \mathrm{~h}$

\begin{tabular}{|c|c|c|c|c|c|c|c|c|c|}
\hline \multirow{2}{*}{$\begin{array}{l}\text { Time of } \\
\text { Incubation }\end{array}$} & \multirow{2}{*}{ Feed } & \multicolumn{4}{|c|}{ DM degradability } & \multicolumn{4}{|c|}{ Partitioning factor $(\mathrm{mg} / \mathrm{ml})$} \\
\hline & & control & PVPP & PEG & mean & control & PVPP & PEG & mean \\
\hline \multirow[t]{6}{*}{$24 \mathrm{~h}$} & Feed A & 0.411 & 0.307 & 0.410 & $0.376^{\mathrm{B}}$ & 7.54 & 4.97 & 4.74 & $5.75^{\mathrm{B}}$ \\
\hline & Feed B & 0.268 & 0.227 & 0.214 & $0.236^{\mathrm{C}}$ & 11.73 & 5.52 & 4.88 & $7.38^{\mathrm{A}}$ \\
\hline & Feed C & 0.535 & 0.494 & 0.591 & $0.540^{\mathrm{A}}$ & 3.86 & 3.28 & 4.01 & $3.71^{\mathrm{C}}$ \\
\hline & Feed D & 0.463 & 0.527 & 0.642 & $0.544^{\mathrm{A}}$ & 5.75 & 4.43 & 5.39 & $5.19^{\mathrm{B}}$ \\
\hline & Feed E & 0.512 & 0.526 & 0.660 & $0.566^{\mathrm{A}}$ & 6.06 & 4.50 & 6.11 & $5.56^{\mathrm{B}}$ \\
\hline & mean & $0.437^{\mathrm{b}}$ & $0.416^{\mathrm{b}}$ & $0.503^{\mathrm{a}}$ & - & $6.98^{\mathrm{a}}$ & $4.54^{b}$ & $5.02^{b}$ & - \\
\hline \multirow[t]{6}{*}{$96 \mathrm{~h}$} & Feed A & 0.517 & 0.443 & 0.491 & $0.484^{\mathrm{B}}$ & 4.09 & 3.18 & 3.09 & $3.47^{\mathrm{A}}$ \\
\hline & Feed B & 0.297 & 0.282 & 0.264 & $0.281^{\mathrm{C}}$ & 4.49 & 3.07 & 2.82 & $3.46^{\mathrm{A}}$ \\
\hline & Feed C & 0.783 & 0.742 & 0.796 & $0.774^{\mathrm{A}}$ & 2.97 & 2.70 & 2.93 & $2.87^{\mathrm{B}}$ \\
\hline & Feed D & 0.721 & 0.745 & 0.821 & $0.763^{\mathrm{A}}$ & 3.54 & 3.09 & 3.42 & $3.35^{\mathrm{A}}$ \\
\hline & Feed E & 0.750 & 0.757 & 0.832 & $0.780^{\mathrm{A}}$ & 3.58 & 3.17 & 3.56 & $3.44^{\mathrm{A}}$ \\
\hline & mean & $0.614^{\mathrm{b}}$ & $0.594^{\mathrm{c}}$ & $0.641^{\mathrm{a}}$ & - & $3.74^{\mathrm{a}}$ & $3.05^{\mathrm{b}}$ & $3.16^{\mathrm{b}}$ & - \\
\hline
\end{tabular}

Conclusion In bioassays with binding assays, it is not recommended to evaluate the alterations in degradability as a tool to evaluate feed quality because there is an unavoidable contamination of the non degraded residue.

Acknowledgements The authors gratefully acknowledge funding from CNPq and FAPESP.

\section{References}

Bueno, I.C.S., Vitti, D.M.S.S., Louvandini, H. and Abdalla, A.L. 2008. Animal Feed Science and Technology. 141, 153170.

SAS Institute, 2000. SAS System for Windows. Release 8,01. Cary. 